\title{
Deep brain stimulation for the treatment of Parkinson's disease: efficacy and safety
}

This article was published in the following Dove Press journal:

Degenerative Neurological and Neuromuscular Disease

3 September 2012

Number of times this article has been viewed

\author{
Nader Pouratian ${ }^{1,2}$ \\ Sandeep Thakkar ${ }^{3}$ \\ Won Kim' \\ Jeff M Bronstein ${ }^{3-5}$ \\ 'Departments of Neurosurgery, \\ ${ }^{2}$ Bioengineering, ${ }^{3}$ Neurology, ${ }^{4}$ Brain \\ Research Institute, David Geffen \\ School of Medicine at UCLA \\ (University of California, Los Angeles), \\ Los Angeles, ${ }^{5}$ Veterans Administration, \\ Southwest Parkinson's Disease \\ Reseach, Education, and Clinical \\ Center Los Angeles, CA, USA
}

Correspondence: Jeff M Bronstein

Department of Neurology,

David Geffen School of Medicine

at UCLA, 710 Westwood Plaza,

A-153, Los Angeles, CA 90095, USA

Tel + I 3102069799

Fax +I 310 2069819

Email jbronste@ucla.edu

\begin{abstract}
Deep brain stimulation (DBS) surgery has become increasingly utilized in the treatment of advanced Parkinson's disease. Over the past decade, a number of studies have demonstrated that DBS is superior to best medical management in appropriately selected patients. The primary targets for DBS in Parkinson's disease include the subthalamic nucleus and the internal segment of the globus pallidus, both of which improve the cardinal motor features in Parkinson's disease. Recent randomized studies have revealed that both targets are similarly effective in treating the motor symptoms of Parkinson's disease, but emerging evidence suggests that the globus pallidus may be the preferred target in many patients, based on differences in nonmotor outcomes. Here, we review appropriate patient selection, and the efficacy and safety of DBS therapy in Parkinson's disease. Best outcomes are achieved if the problems of the individual patient are considered when evaluating surgical candidates and considering whether the subthalamic nucleus or the globus pallidus internus should be targeted.
\end{abstract}

Keywords: Parkinson's disease, deep brain stimulation, subthalamic nucleus, globus pallidus, dyskinesia

\section{Introduction}

The surgical management of Parkinson's disease has had a punctuated evolution over the last century, driven by both advances and shortcomings of medical therapy, as well as advances in stereotactic technology and technique. The intimate relationship between this evolution and the availability of medical therapies highlights the current overall goal of clinical care of achieving symptomatic disease management in this patient population.

Early surgical therapies for movement disorders date back to the late 19th and early 20th centuries, and include extirpations of the precentral gyrus, ${ }^{1}$ rhizotomies, ${ }^{2}$ sympathetic ganglionectomies, ${ }^{3}$ and posterolateral cordotomy. ${ }^{4}$ Because of the relative absence of medical treatment, surgical therapies persisted but generally shifted towards targeting the extrapyramidal system. Before the advent of stereotaxis, Myers performed open cranial procedures to resect the head of the caudate and parts of the putamen and interrupt portions of the internal capsule and ansa lenticularis. ${ }^{5}$ Despite efficacy, these procedures were largely abandoned due to high surgical mortality $(>10 \%)$.

The advent of stereotaxis, or the ability to target structures deep within the human brain precisely, revolutionized the surgical management of movement disorders, especially Parkinson's disease. In 1956, Narabayashi et al reported their first case of chemical pallidotomy in patients with Parkinson's disease, ${ }^{6}$ and Guiot and Brion reported electrical coagulation of the pallidum. ${ }^{7}$ Pallidotomy became a popular 
procedure in the $1950 \mathrm{~s}$, with the target in the anterodorsal part of the pallidum. With greater experience, the target gradually moved to the posteroventral pallidum, with better results. At the same time, ventrolateral thalamotomy was also described in the 1950s to control tremor dramatically, but did not improve other cardinal features of Parkinson's disease. $^{8}$

Despite the success and efficacy of these stereotactic procedures, enthusiasm for surgical treatment of Parkinson's disease diminished when levodopa was introduced in the early 1970s. The limitations of levodopa soon became apparent, particularly that of motor fluctuations. However, it was not until 1992 that Laitinen et al in Sweden reported the benefits of pallidotomy for not only treating the cardinal features of Parkinson's disease, but also in achieving greater control of tremor and levodopa-induced dyskinesias. ${ }^{9}$ As a result, for most of the 1990s, posteroventrolateral pallidotomy emerged as the procedure of choice for patients with Parkinson's disease whose symptoms were not adequately controlled pharmacologically. Due to concerns about an increased risk of complications from bilateral surgery, unilateral procedures were primarily performed, with benefits limited to the contralateral side.

The concept of stimulation rather than ablation of deep brain structures for the treatment of movement disorders only emerged in $1975 .{ }^{10}$ However, deep brain stimulation (DBS) was initially targeted at the thalamic nuclei before shifting focus back to the pallidum (globus pallidus internus) as well as the subthalamic nucleus. ${ }^{11}$ DBS was seen as a significant advance over ablative procedures because of the reversibility of the procedure as well as the ability to modulate therapy, potentially providing more therapeutic options by minimizing the side effects of surgical therapy. For these very same reasons, DBS for Parkinson's disease made it possible to offer bilateral therapy with minimization of the adverse events seen with bilateral pallidotomy. The US Food and Drug Administration approved DBS as a treatment for Parkinson's disease in 2002 and since then, over 80,000 procedures have been performed worldwide. Despite the fact that DBS of both the globus pallidus internus and subthalamic nucleus were approved for the treatment of Parkinson's disease, the subthalamic nucleus has been the target of choice for most neurosurgeons and neurologists. Recent randomized trials comparing the efficacy and side effects of therapy at both targets add new data when considering target selection.

In this review, we discuss patient selection for DBS surgery, comparison of DBS with best medical management, target selection, and adverse events. Given that several aspects of DBS therapy have been reviewed elsewhere and little has changed in the past few years, ${ }^{12-14}$ our discussion places particular emphasis on target selection and the safety of these procedures.

\section{Patient selection}

Appropriate patient selection for surgery is essential for a good outcome, with more than $30 \%$ of DBS failures attributed to inappropriate indications for surgery. ${ }^{15}$ Pharmacologic management remains first-line therapy for patients with Parkinson's disease. DBS therapy should not be considered for those patients whose symptoms are adequately controlled with medical therapy. Selection of appropriate candidates for surgery should be based on whether the problematic symptoms that are not adequately controlled with medications are responsive to DBS and whether the risks of surgery are outweighed by the potential benefits. In general, DBS treats the same Parkinson's disease symptoms as levodopa, except that DBS also helps reduce dyskinesias and some non-doparesponsive tremors. Thus, good candidates for DBS are ones with marked motor fluctuations (significant off-time and on-time with troublesome dyskinesias) and tremors that do not respond adequately to medication. Other nondopa-responsive symptoms, such as poor cognition, postural instability, dysarthria, dysphagia, and dysautonomia do not improve with DBS, and can even get worse. Therefore, if these are the patient's disabling symptoms, DBS should not be considered.

In general, most experts agree that the best candidates for DBS are patients with Parkinson's disease whose therapies have been medically optimized, but they continue to suffer from disabling motor symptoms that respond to levodopa, and are without significant cognitive or psychiatric problems. ${ }^{16}$ Most centers do not advise surgery in patients with a diagnosis of Parkinson's disease for less than 5 years because Parkinson-plus syndromes can often mimic Parkinson's disease in the early years and are less responsive to DBS, although this should not be used as an absolute criterion. ${ }^{16}$ Although age older than 70 years is often discussed as a relative contraindication, a randomized study suggests that older patients (over 70 years) do improve with DBS almost as much as younger patients, without increased risk of surgical complications. ${ }^{12,17}$ Therefore, age should not be used as an absolute exclusion criterion for surgery. ${ }^{18-21}$

The risk of complications of the surgical procedure also needs to be considered. Not surprisingly, adverse events are much more common with surgery compared with best medical management, although most resolve within 
6 months following surgery. ${ }^{17,22}$ In general, cognitively impaired patients are not good candidates for DBS because dementia is usually the most disabling feature of Parkinson's disease and some aspects of cognitive function may worsen after surgery. ${ }^{17,22}$ Similarly, worsening depression and an increased risk of suicide have been reported with DBS of the subthalamic nucleus, and depression should be adequately treated prior to surgery. ${ }^{17,22-24}$ Because there is no absolute consensus criteria in terms of standardized tests, the preoperative evaluation should be made by a team of neurologists, DBS-trained surgeons, and neuropsychologists experienced in movement disorders. ${ }^{12}$

\section{Efficacy of DBS for Parkinson's disease}

Determining the efficacy of a surgical treatment compared with best medical therapy is challenging because it is difficult to blind patients and evaluators to the treatment modality. These biases can heavily favor surgical treatments and, therefore, we must evaluate unblinded trials with great caution. ${ }^{25}$ Despite these limitations, DBS in properly selected patients appears to provide significant benefits over best medical management alone. In the first large trial comparing DBS of the subthalamic nucleus with best medical therapy, Deuschl et al reported that DBS was superior in measures of quality of life and motor function. This study was an unblinded trial with a randomized-pairs design (DBS of the subthalamic nucleus versus best medical therapy) conducted at 10 academic centers in Germany and Austria. ${ }^{22}$ After 6 months, the Parkinson's Disease Questionnaire favored DBS in 50 of 78 pairs and improved by $24 \%$, while the best medical therapy group did not change. Similarly, the motor part of the Unified Parkinson's Disease Rating Scale (UPDRS-III) improved more often in the DBS group (55 of 78 pairs). On average, the UPDRS-III off medications improved by $40 \%$ with DBS compared with no change in the best medical therapy group. The UPDRS-III on medications was also improved with DBS, with most of the benefit due to reduced medication-induced dyskinesias. Patient diaries revealed over 4 hours of more good "on" time with DBS and no improvement with best medical therapy. The cost of these benefits with DBS was an increased risk of serious adverse events (see Safety section). This study clearly demonstrated the benefits of DBS in the majority of patients, but the results should be viewed with some caution because neither the patients nor evaluators were blinded. Similar results were found in a randomized, open-label, multicenter trial (PD SURG) comparing DBS (174 of 178 received DBS to the subthalamic nucleus) versus best medical therapy. ${ }^{26}$ DBS was associated with an improved quality of life and scores for activities of daily living but, not unexpectedly, surgery was associated with additional risks.

A more recent study comparing best medical therapy with DBS (of both the subthalamic nucleus and globus pallidus internus) also demonstrated that DBS was superior using a randomized design and blinded evaluators. ${ }^{17} \mathrm{~A}$ total of 255 patients with advanced Parkinson's disease from seven Veterans Affairs and six university hospitals were randomized to best medical therapy or DBS (further randomized to DBS of the subthalamic nucleus or globus pallidus internus) and assessed using motor diaries at 6 months, with the primary endpoint being time spent "on" without disabling dyskinesias (referred to as the Veterans Administration/ National Institute of Neurological Disorders and Stroke sponsored trial, VA/NINDS). Similar to the study by Deuschl et al, DBS therapy resulted in an average of 4.6 more hours in the best "on" condition compared with no change in the best medical therapy group. Off medication motor function (29\%) and measures of quality of life (18\%) were also improved for DBS compared with best medical therapy, but there was no improvement in motor function on medication.

Qualitatively, the results from the two large studies comparing DBS with best medical therapy were very similar, but the degree of improvement was slightly less in the latter study, which may be in part due to elimination of treatment bias as a result of the double-blind design. The other major difference in the studies was use of both the globus pallidus internus and subthalamic nucleus targets in the latter study, while the former study only included the subthalamic nucleus target. However, this difference in targeting could not account for the difference in efficacy, because it was later found that both targets were equally effective in these patients by these measures. ${ }^{27}$ Others have cited potential differences in the precision of surgical targeting and multidisciplinary management of DBS patients. Even if this were the case, the results of the latter study are likely more practical and useful, given that at a population level, patients are likely to undergo DBS surgery at a variety of centers with varied experience.

While these randomized trials have clarified the benefits of DBS with respect to management of overall motor symptoms and it is clear that the three cardinal signs of Parkinson's disease (tremor, bradykinesia, rigidity) as well as medication-induced dyskinesias all respond to DBS, the various motor symptoms of Parkinson's disease may respond differentially based on target selection or the location of 
stimulation within the target of interest. ${ }^{28,29}$ In particular, there is ongoing discussion concerning the relative efficacy of stimulating the subthalamic nucleus versus the globus pallidus internus in treating tremor-dominant symptoms, freezing, and medication-induced dyskinesias.

Based on individual experiences and a handful of relatively small case series, ${ }^{30-33}$ stimulation of the subthalamic nucleus is believed to be very effective for tremor suppression, even in patients whose tremor is refractory to medical treatment. By extension, it is assumed that stimulation of the subthalamic nucleus is superior to stimulation of the globus pallidus internus for tremor suppression. Despite this assumption, it is also known that pallidal stimulation can result in significant control of tremor. ${ }^{34}$ Unfortunately, there are very few head-to-head comparisons of these targets with respect to tremor control, but data from the VA/NINDS showed no significant differences between the two targets, although there was a trend favoring the subthalamic nucleus. ${ }^{35}$ Despite lack of comparative efficacy, there is evidence to suggest that stimulation of the more dorsal components of the subthalamic nucleus are more effective at controlling tremor than more ventral stimulation. ${ }^{29}$

As with tremor, there are a few reports supporting the superiority of stimulation of the subthalamic nucleus for treating freezing of gait. The most convincing study is that reported by Moreau et al who found that stimulation of the subthalamic nucleus can be specifically modulated to improve freezing symptoms.$^{36}$ However, the stimulation parameters that were particularly effective for treating gait freezing were atypical, largely being low-frequency, high-amplitude stimulation, rather than high-frequency, normal-amplitude stimulation. Despite this prevailing bias, in the most recent randomized controlled trial comparing stimulation of the subthalamic nucleus versus the globus pallidus internus, while there was a slightly decreased incidence of freezing phenomenon and gait disturbance in the subthalamic nucleus group than the globus pallidus internus group, this was not statistically significant. ${ }^{27}$

Finally, given that medically refractory motor fluctuations and on-time dyskinesias are one of the primary indications for DBS, it is important to compare the relative efficacy of stimulation of the subthalamic nucleus and globus pallidus internus in controlling these disabling symptoms. In all blinded assessments comparing the two targets, both sites of stimulation were equally effective in controlling dyskinesias. ${ }^{27,37,38}$ In the most recent and largest randomized trial, the incidence of troublesome dyskinesias and dystonia was not significantly different between the two groups. ${ }^{27,35}$
Despite the lack of a difference, the mechanisms by which dyskinesias are controlled are likely to be different. While stimulation of the globus pallidus internus has a primary effect of suppressing dyskinesias, stimulation of the subthalamic nucleus likely reduces dyskinesias secondary to a relative increase in medication reduction compared with stimulation of the globus pallidus internus. ${ }^{39,40}$

Almost every study of DBS to the subthalamic nucleus reports significant reduction in use of medications for Parkinson's disease, but reports on the effect of DBS to the globus pallidus internus on medication use are less consistent. Burchiel et al reported a 51\% reduction of levodopa equivalents 12 months after DBS to the subthalamic nucleus, similar to several other studies, but no reduction after DBS to the globus pallidus internus. ${ }^{38}$ In the much larger VA/NINDS study, DBS to the subthalamic nucleus resulted in a $32 \%$ decrease at 24 months, and a $36 \%$ decrease at 36 months post-implantation, while DBS to the globus pallidus internus resulted in an $18 \%$ decrease at both 24 and 26 months. ${ }^{17,27,35}$ Despite differences in quantitative results from several studies, it is generally accepted that reductions in Parkinson's disease medications are greater with DBS to the subthalamic nucleus compared with DBS to the globus pallidus internus. ${ }^{12}$

\section{Safety of DBS in Parkinson's disease}

Adverse events from DBS in Parkinson's disease are relatively common, but the reported frequency of these adverse events has been variable in the literature. Reasons for this variability likely stem from the fact that most of the adverse event data come from open-label studies, with technologic advances over time and lack of standardized reporting criteria. Surgery-related adverse events are often most feared because they can lead to permanent sequelae while stimulation-related adverse events are reversible.

\section{Surgery-related complications Death}

The American Academy of Neurology released an evidencedbased practice parameter in 2006 reporting a rate of $0.6 \%$ death. ${ }^{41}$ The frequency of death related to surgery has ranged from $0 \%$ to $4.4 \%{ }^{17,42,43}$ Variability in death rates associated with DBS can be explained in part by the variable inclusion of perioperative complications, such as myocardial infarction, pneumonia, and pulmonary embolism..$^{15,42,44-46} \mathrm{~A}$ low risk of death related to DBS (within 1 month of surgery) is supported by recent reports from large multicenter studies. Deuschl et al reported two deaths related to surgery (one hemorrhage 
and one pneumonia, 2.5\%). ${ }^{47}$ Weaver et al reported only one surgery-related death (hemorrhage) in 121 patients $(0.8 \%)$, and Williams et al reported one death related to surgery in 183 patients $(0.5 \%) .{ }^{17,26}$

\section{Hemorrhage}

The rate of intracerebral hemorrhage related to DBS surgery remains relatively low overall, with rates ranging from $0 \%$ to $4.5 \% .{ }^{17,20,48,49}$ On average, symptomatic intracerebral hemorrhage occurs in approximately $2 \%$ of all procedures, and asymptomatic intracerebral hemorrhage occurs in 1.3\% of procedures. ${ }^{17}$ One meta-analysis of 6237 patients estimated the per-trajectory intracerebral hemorrhage rate to be $1.57 \% .{ }^{17,50}$ In one large multicenter study, Deuschl et al reported asymptomatic intracerebral hemorrhage in 2.6\% of patients and no symptomatic intracerebral hemorrhage. ${ }^{22}$ More recent large multicenter trials did not distinguish between symptomatic and asymptomatic intracerebral hemorrhage, but also reported relatively low rates of $2.2 \%$ and $2.0 \% .^{26,27}$

It is not surprising that symptomatic intracerebral hemorrhage results in poorer outcomes. The implications of asymptomatic versus symptomatic hemorrhage also lengthen hospital stay, with an increased likelihood of being discharged to a rehabilitation center or skilled nursing facility rather than discharged home. In a large meta-analysis, the mean duration of hospitalization in symptomatic hemorrhage cases was 8.2 days compared with 2.7 days in those without hemorrhage, with less than $1 \%$ of all patients incurring a permanent neurologic deficit. $27,50,51$ Given the low rate of intracerebral hemorrhage, it is difficult to identify factors that alter risk. The analysis by Sansur et al suggested that a patient history of hypertension was the most significant factor associated with intracerebral hemorrhage, but older age and male gender were also significantly associated with intracerebral hemorrhage. ${ }^{51}$ Target locations, use of microelectrode recordings, and prior use of anticoagulant therapy were not associated with an increased risk of intracerebral hemorrhage. Conversely, the analysis by Kimmelman et al suggested that use of microelectrode recordings increases the risk of intracerebral hemorrhage, but found no relationship between intracerebral hemorrhage and gender, age, or duration of disease. ${ }^{50}$ Recently, Zrinzo et al reviewed the incidence of hemorrhagic complications with DBS in their series and performed a systematic review of the literature. They estimated the overall risk of symptomatic hemorrhage to be $2.1 \%$ and asymptomatic hemorrhage to be $1.9 \% .{ }^{52}$ They also found that hypertension and age were the most important patient-related factors associated with an increased risk of hemorrhage, and use of microelectrode recordings and number of microelectrode recording penetrations, as well as sulcal or ventricular involvement by the trajectory, were technical factors increasing the risk of hemorrhage.

\section{Infections}

Infection is a major safety concern with any procedure involving implantable hardware, and DBS is no exception. The reported rates of infection in DBS vary considerably, but infection remains the most common surgical complication. The existing literature reports that DBS surgery infection rates vary between $0 \%$ and $15 \%$ per patient and $0 \%$ and $9.7 \%$ per electrode. ${ }^{27,44}$ The variability in reported infection rates is in part attributable to variability in the definition of infection across studies. For example, some include device-related erosion as an infectious complication while others do not. Likewise, some include superficial inflammatory changes at incision sites as an infectious complication. Other authors in the literature restrict the classification to cases with evidence of infection based on positive cultures. ${ }^{27,44,53,54}$ Perhaps the best assessment of overall infection rates is provided by a recent meta-analysis of 35 open-label studies $(n=3550)$, in which an average infection rate of $4.7 \%$ was reported in patients undergoing DBS. ${ }^{27,55}$

Despite this average reported rate in open-label studies, there were consistently higher reported rates of postoperative infection in more recent controlled studies. In the PD-SURG trial that involved 13 centers in the UK, the infection rate was $8.7 \% .{ }^{26}$ Similarly, $7.7 \%$ of patients incurred an infection in the multicenter VA/NINDS-sponsored trial ${ }^{27}$ (with similar rates of infection in the subthalamic nucleus and globus pallidus internus groups). In a well controlled single-center study, Okun et al reported a rate of infection of $7.6 \%$, with no significant difference between subthalamic nucleus or globus pallidus internus groups. ${ }^{56}$ On the other hand, the infection rate was only $2.6 \%$ in patients receiving DBS at 10 academic centers in Germany and Austria, and 2.9\% in patients operated on at eight European centers. ${ }^{22,57}$

Most studies do not report the timing or location of hardware-related infections, although the majority consider the risk to be highest in the first month following surgery. ${ }^{55}$ The intracranial components of DBS appear to be the least likely to become infected. In the meta-analysis by Hamani and Lozano of 10 open-label studies reporting hardware complications, the connector was the most frequent site of infection, followed by the implantable programmable generator pocket, ${ }^{58}$ although in another large series, the 
implantable programmable generator pocket was the most common site of initial infection. ${ }^{53,59}$ Despite several reports and systematic analyses of infection rates, there is a relative absence of even unblinded studies evaluating interventions to reduce infections. However, Miller et al have reported a significant reduction in infections with local application of neomycin-polymyxin. ${ }^{60}$

Despite the variability in all of these reports, it is clear that infection remains the most common serious complication of DBS surgery. It is our opinion that most of the variability comes from nonsystematic reporting and record-keeping, but undoubtedly, variations in surgical technique play a role.

\section{Other hardware-related complications}

Lead fractures, migration, and erosions are relatively rare with DBS, and recent hardware improvements in fixation devices and lower profiles of the connector have certainly reduced these risks even further. In an attempt to estimate the prevalence of hardware-related complications, Videnovic and Metman performed an analysis of adverse events related to DBS reported in the literature between 1996 and 2007. They reported that the average lead fracture rate was $0.7 \%, 0.6 \%$ for migration, $0.08 \%$ for erosion, and $1.0 \%$ for malfunction of the implantable programmable generator. ${ }^{61}$ However, in the more recent multicenter VA/NINDS study, device-related complications were only $0.44 \%$, supporting the concept that the frequency of hardware complications is decreasing. ${ }^{27}$ Most reports on DBS in the past few years do not even mention lead fracture, migration, or erosion, reflecting the rarity of these complications in recent times. There are few data on device-related complications for specific Medtronic models, but complications related to the St Jude Libra DBS device were $2 \%$ for lead migration, $1 \%$ for lead malfunction, and less than $1 \%$ of lead erosion. ${ }^{62}$

\section{Other surgery-related complications}

Other surgery-related complications are rare, with surgical complication rates ranging from $0.1 \%$ for cerebrospinal fluid leak, $0.4 \%-0.06 \%$ for pneumonia, and $0.5 \%-0.1 \%$ for pulmonary embolism. ${ }^{26,27,58,63}$ The reported incidence of postoperative seizures has varied considerably from $0 \%$ to $4 \%$, although rates have been approximately $2 \%$, with the risk of epilepsy essentially being nil. ${ }^{26,27,43,63-65}$

\section{Stimulated-related adverse events}

In addition to the surgical complications associated with implanting DBS electrodes, numerous behavioral and motor adverse effects have been observed. These include depression, anxiety, mania, impulsivity, and impulse control disorders, speech and language difficulties, decreases in various measures of cognitive performance, and postural instability with increased falls. ${ }^{65-67}$ Some of these adverse effects are transient, and resolve readily within minutes to days following stimulation. Others are more insidious in nature, and are only detected after months of follow-up with comprehensive cognitive, psychiatric, and neurologic testing.

The vast majority of reports of neuropsychologic and neuropsychiatric side effects of DBS for Parkinson's disease are based on studies focusing on stimulation of the subthalamic nucleus, as reviewed elsewhere. ${ }^{68}$ On account of the known connectivity of the ventral subthalamic nucleus within the limbic circuitry ${ }^{65,69,70}$ and the well recognized behavioral and neuropsychologic sequelae that may result from the reduction in dopaminergic medications that is made possible after DBS to the subthalamic nucleus, ${ }^{65,71,72}$ investigators have focused on this patient population in regards to their predisposition to and prevalence of neurocognitive and neuropsychiatric dysfunction following DBS. However, early studies were limited in their clinical implications because most of the reports were based on small case series, with controls consisting only of age-matched patients with Parkinson's disease receiving best medical therapy ${ }^{65,73-77}$ or internal controls before and after implantation. ${ }^{65,78-83}$ However, recent, large, multicenter prospective studies comparing the clinical outcomes of these two stimulation sites have allowed a more thorough objective comparison of the neurocognitive effects of DBS at each target. ${ }^{27}$

\section{Depression}

A considerable number of small case series have reported on the risk of depression with DBS, with a recent literature review reporting a postoperative incidence of $1.5 \%-25 \% .{ }^{27,68} \mathrm{~A}$ metaanalysis of these early studies, including 1398 patients with DBS to the subthalamic nucleus, gave greater insight into this broad range, that likely varied on account of disparate cohort sizes, and proposed an $8 \%$ incidence of postoperative depression through retrospective analysis. ${ }^{27,66}$ However, based on these studies, it is difficult to ascertain whether mood changes were directly attributable to DBS on account of reduction in dopaminergic medications, ${ }^{27,71}$ or simply a manifestation of disease progression. ${ }^{27,84,85}$ Moreover, implications drawn from previous studies that used age-matched controls should be interpreted with caution because these controls are generally patients not being evaluated for surgery, and may have differing degrees of disease severity. ${ }^{27,77,84,86}$ 
The recent randomized DBS trials in Parkinson's disease have added additional insight into the question of mood changes after DBS. ${ }^{22,27,85}$ Data emerging from these randomized controlled trials failed to show significant differences in depression scores between the medical and surgical arms at 6 months follow-up. These findings were further corroborated by a large multicenter, randomized, controlled trial including patients receiving best medical therapy, DBS to the globus pallidus, or DBS to the globus pallidus internus, which did not find any difference in rates of depression at 6-month follow-up. ${ }^{17}$ However, follow-up analysis comparing the globus pallidus internus and the subthalamic nucleus targets after 24 months demonstrated an increased incidence of postoperative depression in patients who received DBS to the subthalamic nucleus. ${ }^{27}$ Given the longer follow-up in the latter report, it is possible that depression in patients who received DBS to the subthalamic nucleus does not manifest until later on, which is supported by reports of initial improvement in mood in relation to improved motor symptoms, with concomitant decreases in mood as symptoms become less responsive to stimulation. ${ }^{27,77}$

In addition to these conflicting reports, other data support the need for further analyses of patients undergoing DBS to appreciate the true incidence of postoperative depression. Large-scale retrospective studies demonstrate that the incidence of attempted and completed suicides in patients with Parkinson's disease who receive DBS to the subthalamic nucleus $(0.9 \%$ and $0.45 \%$, respectively) are higher than that in patients with Parkinson's disease and the general populace. ${ }^{27,87,88}$ Le Jeune et al have also reported that stimulation of the subthalamic nucleus induces changes in regional blood flow (measured using positron emission tomography) that correlate with apathy and depressed mood and are unrelated to changes in dopaminergic medication. ${ }^{89}$ Finally, there have been reports of patients in whom depressed mood can be directly induced and remitted by turning the stimulator on or off. ${ }^{27,90}$ Given the relative paucity of reports investigating rates of depression following DBS to the globus pallidus internus, ${ }^{27,68}$ and the even smaller number reporting significant side effects, ${ }^{27,91}$ the role of DBS in altering mood through stimulation of the globus pallidus internus remains unclear.

\section{Language and speech}

In addition to changes in mood and behavior following DBS, a myriad of other neurocognitive side effects have been reported. Such sequelae include problems with word/ phoneme fluency, verbal/working/visuospatial memory, and measures of executive function. ${ }^{68}$ Many of the early cognitive findings were limited to studies without adequate control groups and with a bias towards groups receiving DBS to the subthalamic nucleus. Despite these limitations, there is a preponderance of studies suggesting that patients experience postoperative decreases in verbal fluency. $27,68,73,75,78,80,82,92,93$ These findings are corroborated by a randomized controlled trial conducted by Witt et al, suggesting that these observations are genuinely an effect of DBS rather than progression of disease in a sicker patient population. ${ }^{85}$ However, this may be on account of a decrease in need for dopaminergic medications following DBS to the subthalamic nucleus (only one globus pallidus internus study reported decreased verbal fluency ${ }^{27,92}$ ), because dopamine agonists have been shown to mediate frontal and prefrontal cognitive measures, including verbal fluency, ${ }^{27,94,95}$ and cessation of these medications may result in a subsequent decline in verbal ability. ${ }^{27,76}$

The effects of DBS on speech have been quite variable, with some reporting improvements and others reporting deterioration, especially with DBS to the subthalamic nucleus. ${ }^{96}$ Few studies have specifically focused on speech, although Tripoliti et al recently reported on the effects of DBS to the subthalamic nucleus on speech in 32 consecutive patients. ${ }^{97}$ They found that most patients showed some deterioration after surgery. Speech intelligibility deteriorated by an average of $14.2 \% \pm 20.15 \%$ off medication and by $16.9 \% \pm 21.8 \%$ on medication one year after DBS to the subthalamic nucleus, while a nonsurgical control group only deteriorated by $3.6 \% \pm 5.5 \%$ and $4.5 \% \pm 8.8 \%$, respectively. Medially located electrodes and high voltage to the left subthalamic nucleus were associated with a significantly higher risk of speech deterioration. Paek et al also concluded that electrode placement is a significant determinant of speech outcomes with DBS to the subthalamic nucleus. ${ }^{98}$ Much less is known about the effects of DBS to the globus pallidus internus on speech. In the VA/NINDS trial, problems with speech as an adverse event were reported in $28 \%$ of globus pallidus internus versus $35 \%$ of subthalamic nucleus patients, but the differences were not significant. ${ }^{27}$ Furthermore, a higher percentage of subthalamic nucleus patients reported an adverse event of speech difficulty, dysphonia, and/or dysarthria in a smaller nonrandomized study, adding further evidence that DBS to the subthalamic nucleus might be associated with more problems with speech than DBS to the globus pallidus internus. ${ }^{63}$ Additional studies are clearly needed to determine the factors that alter speech following DBS.

\section{Gait and falls}

Recent reports suggest that DBS to either target, but particularly the subthalamic nucleus, can result in increased postural 
instability or gait dysfunction. ${ }^{27,99}$ The randomized VA/NINDS trial in fact reported an increased rate of falls, postural instability, and gait dysfunction after DBS compared with best medical therapy, and that patients who underwent stimulation to the subthalamic nucleus experienced a significantly greater number of falls than those with stimulation to the globus pallidus internus. ${ }^{17,27}$ A recent nonrandomized study comparing DBS to the subthalamic nucleus with that to the globus pallidus internus reported similar results, with $34.7 \%$ of patients who underwent DBS to the subthalamic nucleus having worsened postoperative balance and gait dysfunction compared with no patients in the group that underwent DBS to the globus pallidus internus. ${ }^{17,57}$ It is unclear if this is an effect inherent in the stimulation process, or a result of decreased dopaminergic medication, because patients with DBS to the globus pallidus internus appear to be relatively resistant to worsening postural instability or gait dysfunction. ${ }^{17,67}$ While several groups have investigated the potential role of pedunculopontine nucleus stimulation for the treatment of medication-refractory disorders of gait and freezing in patients with Parkinson's disease with inconsistent results, no role for stimulation of the pedunculopontine nucleus has been suggested specifically for treatment of these adverse events related to DBS to the subthalamic nucleus or globus pallidus internus. ${ }^{12,99-101}$

\section{Advances in surgical planning technology}

Advanced neuronavigation systems have revolutionized the field of neurosurgery, significantly improving presurgical planning and visualization. ${ }^{102}$ Likewise, sophisticated neuronavigation systems have been integral to the growth and accessibility of DBS as a major treatment modality for Parkinson's disease (as well as other movement disorders and neurologic and psychiatric diseases). At their core, modern neuronavigation systems allow comprehensive integration of multimodality imaging into surgical targeting and trajectory planning, including precise identification of the anterior and posterior commissures and the midline to facilitate indirect targeting methodologies, as well as direct targeting of surgical targets using advanced magnetic resonance imaging sequences. ${ }^{103-105}$ More importantly, given the accumulating evidence of the importance of trajectory planning to minimize brain shift, ${ }^{106}$ minimize hemorrhagic and ischemic complications, ${ }^{107}$ and improve patient outcomes, ${ }^{108}$ these planning systems allow real-time three-dimensional trajectory reconstructions to minimize sulcal, ventricular, and vascular transgressions. While incorporating these factors into surgical planning has never been shown to alter outcomes, the ease with which they can integrated using advanced neuronavigation and planning stations makes it difficult to argue otherwise. In fact, Beriault et al have recently described a computer-assisted DBS trajectory planning algorithm that optimizes avoidance of critical specific brain structures and have shown in 14 patients that the automated trajectories were at least equivalent if not superior to manual, surgeongenerated trajectories. ${ }^{109}$ Likewise, the integration of tools such as the CranialVault project, which has been developed by the Vanderbilt group and provides a reference system for efficacious targets based on data from over 400 patients, will enable neuronavigation systems to provide not only imageguided planning but also population-based clinical data to help guide a patient's surgical targeting and plan individually. With further identification of critical factors with respect to trajectory planning and targeting, neuronavigation systems will continue to play an increasingly important role in optimizing clinical efficacy and minimizing morbidity.

\section{Conclusion}

DBS is an effective treatment for many medically intractable motor symptoms of Parkinson's disease. In recent years, significant advances have been made both in the hardware and in our understanding of the benefits and limitations of DBS, allowing us to select patients for surgery better and provide more realistic expectations of outcomes. DBS is clearly superior to best medical management in properly selected patients but is associated with additional risks. Infection is the most common serious adverse event encountered, but most adverse events do not result in permanent disability. Recent randomized blinded studies have suggested that DBS to the globus pallidus internus is equally effective in controlling motor symptoms and may be associated with fewer nonmotor side effects. Given the increased risk of neurobehavioral problems with DBS to the subthalamic nucleus, we have been selecting the globus pallidus internus as the surgical target much more frequently than the subthalamic nucleus. Although it is our opinion that the goal of DBS is to improve the patient's quality of life and not necessarily to reduce medication dosages maximally, there are some patients for which DBS to the subthalamic nucleus is the more appropriate target. Thus, both targets should be considered and the final target selection should be based on each patient's individual characteristics.

\section{Acknowledgments}

NP is supported by the UCLA Scholars in Translational Medicine Program and a National Institutes of Health/National Institute of Biomedical Imaging and Bioengineering grant 
(K23EB014326). ST and JMB are supported by the Veterans Administration SW PADRECC.

\section{Disclosure}

The authors report no conflicts of interest in this work.

\section{References}

1. Bucy PC, Case TJ: Tremor, physiologic mechanism and abolition by surgical means. Arch Neurol Psychiatry. 1939;41:721-746.

2. Foerster O. Ueber eine neue operative Methode der Behandlung spastischer Lähmungen mittels. Z Orthop Chir. 1908;22:203-223. German.

3. Rees CE. Observations following sympathetic ganglionectomy in cases of post-encephalitic parkinsonian syndrome. J Nerv Ment Dis. 1934;79:574.

4. Putnam TJ. Treatment of athetosis and dystonia by section of extrapyramidal motor tracts. Arch Neurol Psychiatry. 1933;29: 504-521.

5. Myers HR. Surgical procedure for postencephalitic tremor, with notes on the physiology of premotor fibers. Arch Neurol Psychiatry. 1940;44:445-459.

6. Narabayashi H, Okuma T, Shikiba S. Procaine oil blocking of the globus pallidus. AMA Arch Neurol Psychiatry. 1956;75:36-48.

7. Guiot G, Brion S. Treatment of abnormal movement by pallidal coagulation. Rev Neurol (Paris). 1953;89:578-580. French.

8. Hassler R, Riechert T. Indications and localization of stereotactic brain operations. Der Nervenarzt. 1954;25:441-447. German.

9. Laitinen LV, Bergenheim AT, Hariz MI. Leksell's posteroventral pallidotomy in the treatment of Parkinson's disease. J Neurosurg. 1992;76:53-61.

10. Bechtereva NP, Bondartchuk AN, Smirnov VM, Meliutcheva LA, Shandurina AN. Method of electrostimulation of the deep brain structures in treatment of some chronic diseases. Confin Neurol. 1975;37:136-140.

11. Benabid AL, Pollak P, Gross C, et al. Acute and long-term effects of subthalamic nucleus stimulation in Parkinson's disease. Stereotact Funct Neurosurg. 1994;62:76-84.

12. Bronstein JM, Tagliati M, Alterman RL, et al. Deep brain stimulation for Parkinson disease: an expert consensus and review of key issues. Arch Neurol. 2011;68:165.

13. Fasano A, Daniele A, Albanese A. Treatment of motor and non-motor features of Parkinson's disease with deep brain stimulation. Lancet Neurol. 2012;11:429-442.

14. Lyons MK. Deep brain stimulation: current and future clinical applications. Mayo Clin Proc. 2011;86:662-672.

15. Okun MS, Tagliati M, Pourfar M, et al. Management of referred deep brain stimulation failures: a retrospective analysis from 2 movement disorders centers. Arch Neurol. 2005;62:1250-1255.

16. Lang AE, Houeto JL, Krack P, et al. Deep brain stimulation: preoperative issues. Mov Disord. 2006;21 Suppl 14:S171-S196.

17. Weaver FM, Follett K, Stern M, et al. Bilateral deep brain stimulation vs best medical therapy for patients with advanced Parkinson disease: a randomized controlled trial. JAMA. 2009;301:63-73.

18. Charles PD, Van Blercom N, Krack P, et al. Predictors of effective bilateral subthalamic nucleus stimulation for PD. Neurology. 2002;59:932-934.

19. Vesper J, Haak S, Ostertag C, Nikkhah G. Subthalamic nucleus deep brain stimulation in elderly patients - analysis of outcome and complications. BMC Neurol. 2007;7:7.

20. Ory-Magne F, Brefel-Courbon C, Simonetta-Moreau M, et al. Does ageing influence deep brain stimulation outcomes in Parkinson's disease? Mov Disord. 2007;22:1457-1463.

21. Derost PP, Ouchchane L, Morand D, et al. Is DBS-STN appropriate to treat severe Parkinson disease in an elderly population? Neurology. 2007;68:1345-1355.
22. Deuschl G, Schade-Brittinger C, Krack P, et al. A randomized trial of deep-brain stimulation for Parkinson's disease. $N$ Engl $J$ Med. 2006;355:896-908.

23. Soulas T, Gurruchaga JM, Palfi S, Cesaro P, Nguyen JP, Fenelon G. Attempted and completed suicides after subthalamic nucleus stimulation for Parkinson's disease. J Neurol Neurosurg Psychiatry. 2008;79: 952-954.

24. Berney A, Vingerhoets F, Perrin A, et al. Effect on mood of subthalamic DBS for Parkinson's disease: a consecutive series of 24 patients Neurology. 2002;59:1427-1429.

25. Alterman RL, Tagliati M, Olanow CW. Open-label surgical trials for Parkinson disease: time for reconsideration. Ann Neurol. 2011;70: 5-8.

26. Williams A, Gill S, Varma T, et al. Deep brain stimulation plus best medical therapy versus best medical therapy alone for advanced Parkinson's disease (PD SURG trial): a randomised, open-label trial. Lancet Neurol. 2010;9:581-591.

27. Follett KA, Weaver FM, Stern M, et al. Pallidal versus subthalamic deep-brain stimulation for Parkinson's disease. N Engl J Med. 2010;362: 2077-2091.

28. Mera T, Vitek JL, Alberts JL, Giuffrida JP. Kinematic optimization of deep brain stimulation across multiple motor symptoms in Parkinson's disease. J Neurosci Methods. 2011;198:280-286.

29. Hilliard JD, Frysinger RC, Elias WJ. Effective subthalamic nucleus deep brain stimulation sites may differ for tremor, bradykinesia and gait disturbances in Parkinson's disease. Stereotact Funct Neurosurg. 2011;89:357-364

30. Blahak C, Wohrle JC, Capelle HH, et al. Tremor reduction by subthalamic nucleus stimulation and medication in advanced Parkinson's disease. J Neurol. 2007;254:169-178.

31. Sturman MM, Vaillancourt DE, Metman LV, Bakay RA, Corcos DM. Effects of subthalamic nucleus stimulation and medication on resting and postural tremor in Parkinson's disease. Brain. 2004;127(Pt 9): 2131-2143.

32. Diamond A, Shahed J, Jankovic J. The effects of subthalamic nucleus deep brain stimulation on parkinsonian tremor. J Neurol Sci. 2007;260:199-203.

33. Blomstedt P, Fytagoridis A, Tisch S. Deep brain stimulation of the posterior subthalamic area in the treatment of tremor. Acta Neurochir (Wien). 2009;151:31-36.

34. Jimenez F, Velasco F, Carrillo-Ruiz JD, et al. Comparative evaluation of the effects of unilateral lesion versus electrical stimulation of the globus pallidus internus in advanced Parkinson's disease. Stereotact Funct Neurosurg. 2006;84:64-71.

35. Weaver FM, Follett KA, Stern M, et al. Randomized trial of deep brain stimulation for Parkinson's disease: 36 month outcomes. Neurology. 2012.

36. Moreau C, Defebvre L, Destee A, et al. STN-DBS frequency effects on freezing of gait in advanced Parkinson disease. Neurology. 2008;71:80-84.

37. Moro E, Lozano AM, Pollak P, et al. Long-term results of a multicenter study on subthalamic and pallidal stimulation in Parkinson's disease. Mov Disord. 2010;25:578-586.

38. Burchiel KJ, Anderson VC, Favre J, Hammerstad JP. Comparison of pallidal and subthalamic nucleus deep brain stimulation for advanced Parkinson's disease: results of a randomized, blinded pilot study. Neurosurgery. 1999;45:1375-1382.

39. Moro E, Esselink RJ, Benabid AL, Pollak P. Response to levodopa in parkinsonian patients with bilateral subthalamic nucleus stimulation. Brain. 2002;125(Pt 11):2408-2417.

40. Herzog J, Pogarell O, Pinsker MO, et al. Deep brain stimulation in Parkinson's disease following fetal nigral transplantation. Mov Disord. 2008;23:1293-1296.

41. Pahwa R, Factor SA, Lyons KE, et al. Practice parameter: treatment of Parkinson disease with motor fluctuations and dyskinesia (an evidencebased review): report of the Quality Standards Subcommittee of the American Academy of Neurology. Neurology. 2006;66:983-995. 
42. Anderson VC, Burchiel KJ, Hogarth P, Favre J, Hammerstad JP. Pallidal vs subthalamic nucleus deep brain stimulation in Parkinson disease. Arch Neurol. 2005;62:554-560.

43. Videnovic A, Metman LV. Deep brain stimulation for Parkinson's disease: prevalence of adverse events and need for standardized reporting. Mov Disord. 2008;23:343-349.

44. Boviatsis EJ, Stavrinou LC, Themistocleous M, Kouyialis AT, Sakas DE. Surgical and hardware complications of deep brain stimulation. A seven-year experience and review of the literature. Acta Neurochir (Wien). 2010;152:2053-2062.

45. Blomstedt P, Hariz MI. Hardware-related complications of deep brain stimulation: a ten year experience. Acta Neurochir (Wien). 2005;147:1061-1064.

46. Umemura A, Jaggi JL, Hurtig HI, et al. Deep brain stimulation for movement disorders: morbidity and mortality in 109 patients. J Neurosurg. 2003;98:779-784.

47. Deuschl G, Herzog J, Kleiner-Fisman G, et al. Deep brain stimulation: postoperative issues. Mov Disord. 2006;21 Suppl 14:S219-S237.

48. Foltynie T, Zrinzo L, Martinez-Torres I, et al. MRI-guided STN DBS in Parkinson's disease without microelectrode recording: efficacy and safety. J Neurol Neurosurg Psychiatry. 2011;82:358-363.

49. Maldonado IL, Roujeau T, Cif L, et al. Magnetic resonance-based deep brain stimulation technique: a series of 478 consecutive implanted electrodes with no perioperative intracerebral hemorrhage. Neurosurgery. 2009;65(Suppl 6):196-201.

50. Kimmelman J, Duckworth K, Ramsay T, Voss T, Ravina B, Emborg ME. Risk of surgical delivery to deep nuclei: a meta-analysis. Mov Disord. 2011;26:1415-1421.

51. Sansur CA, Frysinger RC, Pouratian N, et al. Incidence of symptomatic hemorrhage after stereotactic electrode placement. J Neurosurg. 2007;107:998-1003.

52. Zrinzo L, Foltynie T, Limousin P, Hariz MI. Reducing hemorrhagic complications in functional neurosurgery: a large case series and systematic literature review. J Neurosurg. 2012;116:84-94.

53. Sillay KA, Larson PS, Starr PA. Deep brain stimulator hardware-related infections: incidence and management in a large series. Neurosurgery. $2008 ; 62: 360-366$

54. Gorgulho A, Juillard C, Uslan DZ, et al. Infection following deep brain stimulator implantation performed in the conventional versus magnetic resonance imaging-equipped operating room. J Neurosurg. 2009;110:239-246.

55. Bhatia S, Zhang K, Oh M, Angle C, Whiting D. Infections and hardware salvage after deep brain stimulation surgery: a single-center study and review of the literature. Stereotact Funct Neurosurg. 2010;88:147-155.

56. Okun MS, Fernandez HH, Wu SS, et al. Cognition and mood in Parkinson's disease in subthalamic nucleus versus globus pallidus interna deep brain stimulation: the COMPARE trial. Ann Neurol. 2009;65:586-595.

57. Hariz MI, Rehncrona S, Quinn NP, Speelman JD, Wensing C. Multicenter study on deep brain stimulation in Parkinson's disease: An independent assessment of reported adverse events at 4 years. Mov Disord. 2008;23:416-421.

58. Hamani C, Lozano AM. Hardware-related complications of deep brain stimulation: a review of the published literature. Stereotact Funct Neurosurg. 2006;84:248-251.

59. Zhang K, Bhatia S, Oh MY, Cohen D, Angle C, Whiting D. Long-term results of thalamic deep brain stimulation for essential tremor. J Neurosurg. 2010;112:1271-1276.

60. Miller JP, Acar F, Burchiel KJ. Significant reduction in stereotactic and functional neurosurgical hardware infection after local neomycin/ polymyxin application. J Neurosurg. 2009;110:247-250.

61. Videnovic A, Metman LV. Deep brain stimulation for Parkinson's disease: prevalence of adverse events and need for standardized reporting. Mov Disord. 2008;23:343-349.

62. Okun MS, Gallo BV, Mandybur G, et al. Subthalamic deep brain stimulation with a constant-current device in Parkinson's disease: an openlabel randomised controlled trial. Lancet Neurol. 2012;11:140-149.
63. Hariz MI, Rehncrona S, Quinn NP, Speelman JD, Wensing C. Multicenter study on deep brain stimulation in Parkinson's disease: an independent assessment of reported adverse events at 4 years. Mov Disord. 2008;23:416-421.

64. Pouratian N, Reames DL, Frysinger R, Elias WJ. Comprehensive analysis of risk factors for seizures after deep brain stimulation surgery. J Neurosurg. 2011;115:310-315.

65. Vergani F, Landi A, Pirillo D, Cilia R, Antonini A, Sganzerla EP. Surgical, medical, and hardware adverse events in a series of 141 patients undergoing subthalamic deep brain stimulation for Parkinson disease. World Neurosurg. 2010;73:338-344.

66. Temel Y, Kessels A, Tan S, Topdag A, Boon P, Visser-Vandewalle V. Behavioural changes after bilateral subthalamic stimulation in advanced Parkinson disease: a systematic review. Parkinsonism Relat Disord. 2006; $12: 265-272$.

67. St George RJ, Nutt JG, Burchiel KJ, Horak FB. A meta-regression of the long-term effects of deep brain stimulation on balance and gait in PD. Neurology. 2010;75:1292-1299.

68. Voon V, Kubu C, Krack P, Houeto JL, Troster AI. Deep brain stimulation: neuropsychological and neuropsychiatric issues. Mov Disord. 2006;21 Suppl 14:S305-S327.

69. Lambert C, Zrinzo L, Nagy Z, et al. Confirmation of functional zones within the human subthalamic nucleus: patterns of connectivity and sub-parcellation using diffusion weighted imaging. Neuroimage. 2012;60:83-94.

70. Benarroch EE. Subthalamic nucleus and its connections: Anatomic substrate for the network effects of deep brain stimulation. Neurology. 2008;70:1991-1995.

71. Volkmann J, Allert N, Voges J, Weiss PH, Freund HJ, Sturm V. Safety and efficacy of pallidal or subthalamic nucleus stimulation in advanced PD. Neurology. 2001;56:548-551.

72. Krack P, Fraix V, Mendes A, Benabid AL, Pollak P. Postoperative management of subthalamic nucleus stimulation for Parkinson's disease. Mov Disord. 2002;17 Suppl 3:S188-S197.

73. Moretti R, Torre P, Antonello RM, et al. Neuropsychological changes after subthalamic nucleus stimulation: a 12 month follow-up in nine patients with Parkinson's disease. Parkinsonism Relat Disord. 2003; 10:73-79.

74. Morrison CE, Borod JC, Perrine K, et al. Neuropsychological functioning following bilateral subthalamic nucleus stimulation in Parkinson's disease. Arch Clin Neuropsychol. 2004;19:165-181.

75. Castelli L, Rizzi L, Zibetti M, Angrisano S, Lanotte M, Lopiano L. Neuropsychological changes 1-year after subthalamic DBS in PD patients: a prospective controlled study. Parkinsonism Relat Disord. 2010;16:115-118.

76. York MK, Dulay M, Macias A, et al. Cognitive declines following bilateral subthalamic nucleus deep brain stimulation for the treatment of Parkinson's disease. J Neurol Neurosurg Psychiatry. 2008;79: 789-795.

77. Wang X, Chang C, Geng N, et al. Long-term effects of bilateral deep brain stimulation of the subthalamic nucleus on depression in patients with Parkinson's disease. Parkinsonism Relat Disord. 2009;15:587-591.

78. Alegret M, Junque C, Valldeoriola F, et al. Effects of bilateral subthalamic stimulation on cognitive function in Parkinson disease. Arch Neurol. 2001;58:1223-1227.

79. Ardouin C, Pillon B, Peiffer E, et al. Bilateral subthalamic or pallidal stimulation for Parkinson's disease affects neither memory nor executive functions: a consecutive series of 62 patients. Arch Neurol. 1999;46:217-223.

80. Castelli L, Perozzo P, Zibetti M, et al. Chronic deep brain stimulation of the subthalamic nucleus for Parkinson's disease: effects on cognition, mood, anxiety and personality traits. Eur Neurol. 2006;55:136-144.

81. Daniele A, Albanese A, Contarino MF, et al. Cognitive and behavioural effects of chronic stimulation of the subthalamic nucleus in patients with Parkinson's disease. J Neurol Neurosurg Psychiatry. 2003; 74:175-182. 
82. Funkiewiez A, Ardouin C, Caputo E, et al. Long term effects of bilateral subthalamic nucleus stimulation on cognitive function, mood, and behaviour in Parkinson's disease. J Neurol Neurosurg Psychiatry. 2004;75:834-839.

83. Krack P, Batir A, Van Blercom N, et al. Five-year follow-up of bilateral stimulation of the subthalamic nucleus in advanced Parkinson's disease. N Engl J Med. 2003;349:1925-1934.

84. Houeto JL, Mesnage V, Mallet L, et al. Behavioural disorders, Parkinson's disease and subthalamic stimulation. J Neurol Neurosurg Psychiatry. 2002;72:701-707.

85. Witt K, Daniels C, Reiff J, et al. Neuropsychological and psychiatric changes after deep brain stimulation for Parkinson's disease: a randomised, multicentre study. Lancet Neurol. 2008;7:605-614.

86. Daunay B, Lambert P, Jalabert L, et al. Effect of substrate wettability in liquid dielectrophoresis (LDEP) based droplet generation: theoretical analysis and experimental confirmation. Lab Chip. 2012;12:361-368.

87. Voon V, Krack P, Lang AE, et al. A multicentre study on suicide outcomes following subthalamic stimulation for Parkinson's disease. Brain. 2008;131:2720-2728.

88. Appleby BS, Duggan PS, Regenberg A, Rabins PV. Psychiatric and neuropsychiatric adverse events associated with deep brain stimulation: A meta-analysis of ten years' experience. Mov Disord. 2007;22: $1722-1728$.

89. Le Jeune F, Drapier D, Bourguignon A, et al. Subthalamic nucleus stimulation in Parkinson disease induces apathy: a PET study. Neurology. 2009;73:1746-1751.

90. Tommasi G, Lanotte M, Albert U, et al. Transient acute depressive state induced by subthalamic region stimulation. J Neurol Sci. 2008;273:135-138.

91. Rodriguez-Oroz MC, Obeso JA, Lang AE, et al. Bilateral deep brain stimulation in Parkinson's disease: a multicentre study with 4 years follow-up. Brain. 2005;128(Pt 10):2240-2249.

92. Trepanier LL, Kumar R, Lozano AM, Lang AE, Saint-Cyr JA. Neuropsychological outcome of GPi pallidotomy and GPi or STN deep brain stimulation in Parkinson's disease. Brain Cogn. 2000;42:324-347.

93. Schoenberg MR, Mash KM, Bharucha KJ, Francel PC, Scott JG. Deep brain stimulation parameters associated with neuropsychological changes in subthalamic nucleus stimulation for refractory Parkinson's disease. Stereotact Funct Neurosurg. 2008;8:337-344.

94. Cools R, Barker RA, Sahakian BJ, Robbins TW. Enhanced or impaired cognitive function in Parkinson's disease as a function of dopaminergic medication and task demands. Cereb Cortex. 2001;11:1136-1143.

95. Mattay VS, Tessitore A, Callicott JH, et al. Dopaminergic modulation of cortical function in patients with Parkinson's disease. Ann Neurol. 2002;51:156-164

96. Murdoch BE. Surgical approaches to treatment of Parkinson's disease: implications for speech function. Int J Speech Lang Pathol. 2010;12: 375-384.
97. Tripoliti E, Zrinzo L, Martinez-Torres I, et al. Effects of subthalamic stimulation on speech of consecutive patients with Parkinson disease. Neurology. 2011;76:80-86.

98. Paek SH, Han JH, Lee JY, Kim C, Jeon BS, Kim DG. Electrode position determined by fused images of preoperative and postoperative magnetic resonance imaging and surgical outcome after subthalamic nucleus deep brain stimulation. Neurosurgery. 2008;63:925-936.

99. Follett KA, Torres-Russotto D. Deep brain stimulation of globus pallidus interna, subthalamic nucleus, and pedunculopontine nucleus for Parkinson's disease: which target? Parkinsonism Relat Disord. 2012;18 Supp1 1:S165-S167.

100. Khan S, Gill SS, Mooney L, et al. Combined pedunculopontinesubthalamic stimulation in Parkinson disease. Neurology. 2012;78: 1090-1095.

101. Moro E, Hamani C, Poon YY, et al. Unilateral pedunculopontine stimulation improves falls in Parkinson's disease. Brain. 2010; 133(Pt 1):215-224.

102. Risholm P, Golby AJ, Wells W 3rd. Multimodal image registration for preoperative planning and image-guided neurosurgical procedures. Neurosurg Clin N Am. 2011;22:197-206.

103. Nolte IS, Gerigk L, Al-Zghloul M, Groden C, Kerl HU. Visualization of the internal globus pallidus: sequence and orientation for deep brain stimulation using a standard installation protocol at 3.0 Tesla. Acta Neurochir (Wien). 2012;154:481-494.

104. Sudhyadhom A, Haq IU, Foote KD, Okun MS, Bova FJ. A high resolution and high contrast MRI for differentiation of subcortical structures for DBS targeting: the Fast Gray Matter Acquisition T1 Inversion Recovery (FGATIR). Neuroimage. 2009;47 Suppl 2:T44-T52.

105. Vassal F, Coste J, Derost P, et al. Direct stereotactic targeting of the ventrointermediate nucleus of the thalamus based on anatomic 1.5-T MRI mapping with a white matter attenuated inversion recovery (WAIR) sequence. Brain Stimul. February 22, 2012. [Epub ahead of print.]

106. Zrinzo L, van Hulzen AL, Gorgulho AA, et al. Avoiding the ventricle: a simple step to improve accuracy of anatomical targeting during deep brain stimulation. J Neurosurg. 2009;110:1283-1290.

107. Elias WJ, Sansur CA, Frysinger RC. Sulcal and ventricular trajectories in stereotactic surgery. J Neurosurg. 2009;110:201-207.

108. Gologorsky Y, Ben-Haim S, Moshier EL, et al. Transgressing the ventricular wall during subthalamic deep brain stimulation surgery for Parkinson disease increases the risk of adverse neurological sequelae. Neurosurgery. 2011;69:294-299.

109. Beriault S, Subaie FA, Collins DL, Sadikot AF, Pike GB. A multimodal approach to computer-assisted deep brain stimulation trajectory planning. Int J Comput Assist Radiol Surg. June 21, 2012. [Epub ahead of print.]
Degenerative Neurological and Neuromuscular Disease

\section{Publish your work in this journal}

Degenerative Neurological and Neuromuscular Disease is an international, peer-reviewed, open access journal focusing on research into degenerative neurological and neuromuscular disease, identification of therapeutic targets and the optimal use of preventative and integrated treatment interventions to achieve improved outcomes, enhanced

\section{Dovepress}

survival and quality of life for the patient. The manuscript management system is completely online and includes a very quick and fair peer-review system. Visit http://www.dovepress.com/testimonials.php to read real quotes from published authors. 